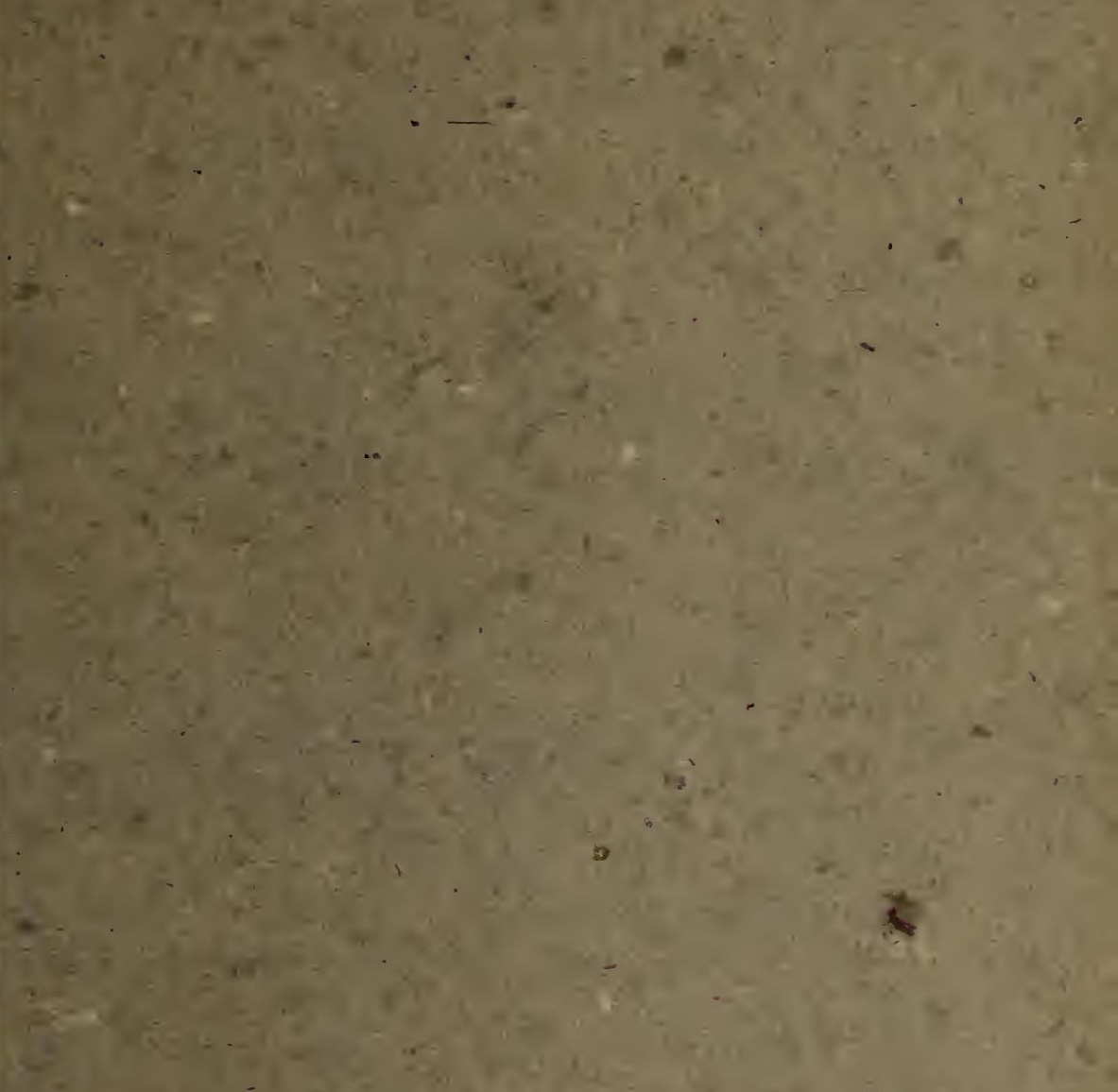


$\mu_{a}-\mu$

HARVARD UNIVERSITY.

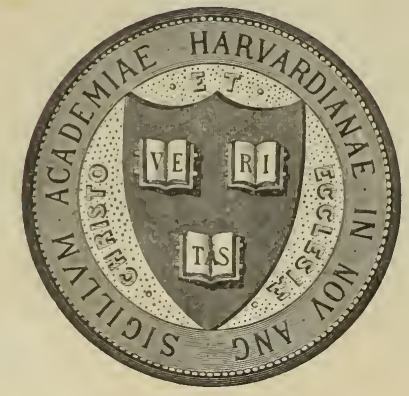

LI B R A R Y

OF TILE

MUSEUM OF COMPARATIVE ZOÖLOGY.

33,593

GIFT OF

Outran Bangs.

April 13, 1909 . 


\section{Discovery of a Little "Opossum Rat" in South America Proves That a Continent Once Stretched Across the Pole to Australia.}

The famous fable tells us how the mountain brought forth a mouse, but even the Imagination of old Asop could not have suggested that a mouse might bring forth a mountain. Yet modern science has now assured us that this miracle has been surpassed in point of actual fact, for a mouse has brought forth, not a mountain merely, but a continent.

At any rate, the mouse has revealed the former existence of a continent where no land has been above the water within the memory of men.

Moreover, the newly found land has a peculiar interest, for it is probably nore other than the long-lost Atlantis, fabled in tradition. Many nations have chronicled the existence of such a land, and philosophers, from Plato to Ignatius Donnelly, have vainly puzzled their heads over its location. And now a mouse reveals the secret which the philosophers could not fathom.

An amateur naturalist, whlle hunting in South America, chanced to hear the natives speak of a very rare species of mouse, which, according to their account, lives in high orush wood, and feeds on birds' eggs, and which they reader this at once suggests a puzzling question: How could a little marsupia adapted for life in tropical or temperate zones make its way across a polar continent, even were the continent avallable?

T'o the geologist, however, this question presents no difficulties. At the time when the ancestors of our little Caenolestes made their way across Antarctica, it was a polar continent, but it had not what we now consider a polar climate. It is well known from evidence given by fossils, that the polar regions once had the climate of temperate, or even of sub tropical zones of today.

In relatively recent times the Antarctic region may have had a climate making it a suitable habitation for creatures that now are forced to confine themselves many degrees nearer the equator. In this day it was that little Caenolestes came across the bridge from Australia to South America.

He did not burn the bridge behind him, but the bridge itself presently sank beneath the ocean, cutting off the retreat just as effectually.

The opossums, long residents of the western hemisphere, are also marsupials, and though they have not the peculiar dentition that marks flrst-cousinship with the Australian branch, yet it seems certain that at some more remote

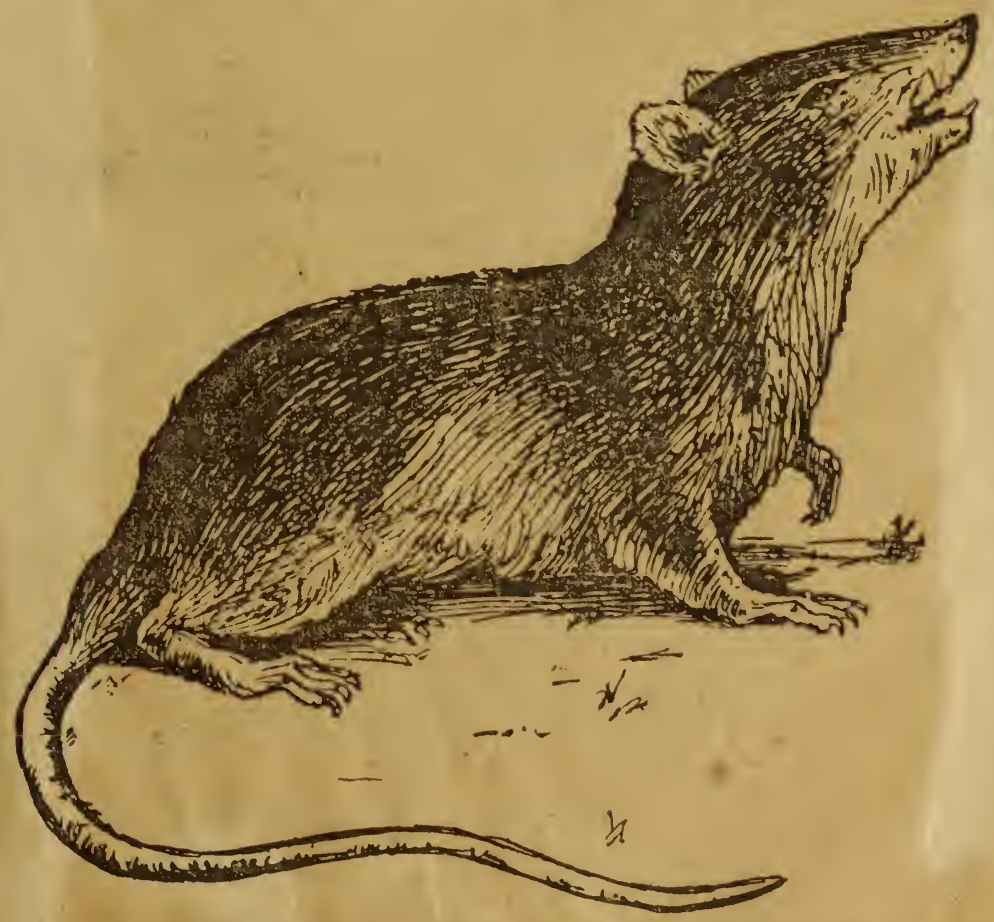




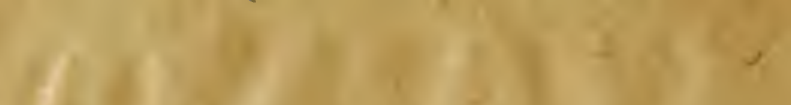

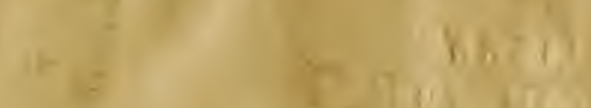

-

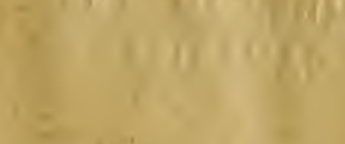

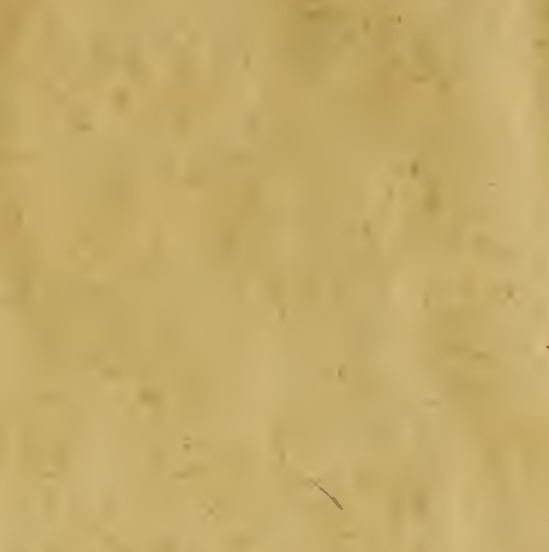

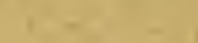

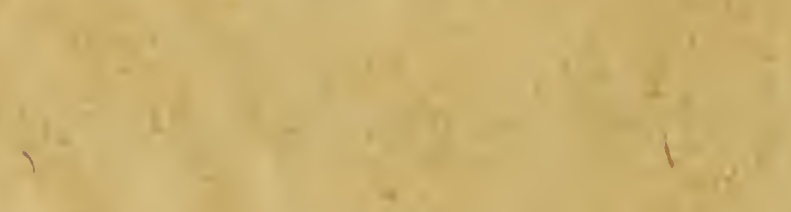

(1)

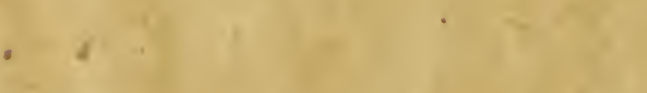<smiles>[CH]1[CH]C[CH]1</smiles><smiles>CCCC</smiles>

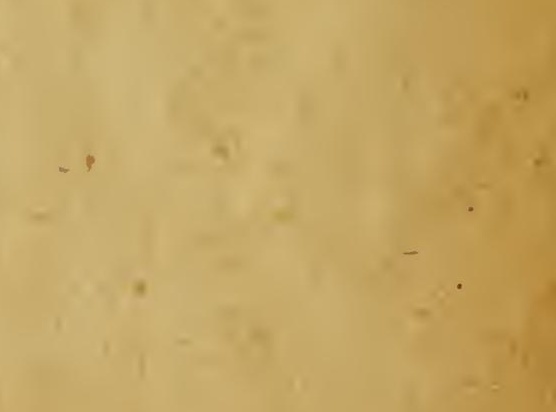


called the raton runcho," or opossum rat.

After much effort, he secured a specimen of this rare rat, near Bogota, and sent it to England, to Prof Oldfield Thomas, the zoologist, who no sooner set eyes on the specimen than he recognized that he had not merely a new species, but a new family of animal, and a wonderful prize.

For to his expert eye it was at once apparent that the new mouse was no mouse at all, but a creature related zoologically to the opossums and kangaroos-in short, a marsupial, a member of the strange tribe of pouched animals of which Australia comes so near having a monopoly.

This in itself was surprising, but careful examination showed that it was only a beginning. For when the skull was critically studied, it showed peculiarities which proved at once to the trained naturalist that the new marsupial was not closely related to the opossums. which hitherto had been supposed to be the only marsupials in existence in the western hemisphere, but to a branch of the family supposed to have been unique to Australia.

Thereby hangs the tale. For, in the opinion of the modern naturalist, such close similarity of structure as this is proof positive of close "blood relationship."

Our newly discovered South American marsupial is first cousin to the diprotodont marsupial of Australia. But how could this be unless South America and Australia have once been joined together?

Clearly they must have been so joined, and the land that joined them must for Australia and South America lie on opposite sides of the globe. Therefore the lost Atlantis which now springs into the lost Atlantis which now springs into little marsupial, was no mere island, but a massive continent.

Just where was this' continent located? A glance at an atlas or globe makes the answer easy. A direct line joining Australia with Patagonia runs through the south pole. In all probability, then, our new-found Atlantis must have been an antarctic continent.

But doubtless to the non-geological period their geneological tree must trace back to the same root.

Prof Lydekker, the famous student of the geographical distribution of animals, thinks he is able to trace the genealogy of the entire family of marsupials, and show that they have a most curious history.

The ancestral home of the tribe, he thinks, was somewhere in southeastern Asia. In that early day all the marsupials dwelt together as one tribe, like the descendants of Noah in the land of Shindar.

But presently there came a confusion of tongues, so to speak, and the marsupials were "scattered abroar upon the face of the earth." One cohort traveled to the west, and finally came to the limits of western Europe. Here for a time they lived as their bones in the rocks still testify, but finally they became exterminated.

The second cohort traveled to the south, across land bridges not now in existence, taking up their main abode in Australia and the neighboring islands, where to this day they reign supreme and from whence, as we have seen, one family at least wandered on across Antarctica, or Atlantis, to South America.

The third cohort moved to the north, coming finally to what now is Berings strait, but what then was a land bridge joining Asia and America. They crossed this bridge, wandered southward along the American coast, spread across to the Atlantic, and took up permanent abode in the soutliein United States.

Later on, when North and South America were joined together, the wandering marsupials continued their journey to the south, finally peopling the southern continent.

By this time millions of years had elapsed since the journeying began over there in Asia. The European marsupials had all become extinct: the Australian branch had evolved into many strange forms, of which the most familiar are the kangaroos, and the American branch had become the opossums.

The discovery of the polar continent just revealed by the little opossum-rat is an achievement of no mean signiflcance. Clearly, little Caenolestes is the Columbus among animals. 

